\title{
O GOVERNO DAS ARMAS DE UMA PROVINCIA DISSIDENTE: UMA BREVE NARRATIVA DA TRAJETÓRIA DO MAJOR PORTUGUÊS JOÃO JOSÉ DA CUNHA FIDIÉ NA INDEPENDÊNCIA DO PIAUII (1822-1823) ${ }^{1}$
}

LUIS CARLOS ALBANO DUARTE SOUSA UNIVERSIDADE FEDERAL DO PIAUÍ TERESINA - PIAUI - BRASIL JOHNY SANTANA DE ARAÚJO** (ID UNIVERSIDADE FEDERAL DO PIAUÍ TERESINA - PIAUI - BRASIL

Este artigo busca, a partir do levantamento de uma série de dados empíricos, construir uma breve narrativa sobre a passagem do major português João José da Cunha Fidié no cargo de Governador das Armas da Província do Piauí, fornecendo bases para importantes compreensões sobre o período da independência. Em contraste com as ações dos líderes dissidentes, como Simplício Dias, João Cândido e outros, questionamos o grau de comprometimento do pragmatismo de Fidié em

\section{RESUMO} relação aos interesses da Coroa portuguesa, vez que sua presença configurava intervenção direta nos rumos políticos do Brasil. Para isso, utilizamos ofícios e correspondências do Arquivo Histórico Ultramarino e do Museu Ozildo Albano, na intenção de apreender as ações e reações desses sujeitos, e suas contradições diante do momento histórico aqui analisado.

Palavras-chave: Governo das Armas; Independência; Piauí.

This article seeks, based on a series of empirical data, to build a brief narrative about the passage of the Portuguese Major João José da Cunha Fidié as the Governor of Arms from the Province of Piauí, providing bases for important understandings about the independence period. In contrast to the actions of dissident leaders, such as Simplício Dias, João Cândido and others, we questioned the commitment degree of Fidié's pragmatism in relation to the Portuguese Crown interests, since his ASTRACT presence represented a direct intervention in the political direction of Brazil. For this, we used letters and correspondence from the Overseas Historical Archive and the Ozildo Albano Museum, in order to apprehend the actions and reactions of these subjects, and their contradictions in light of the historical moment analyzed here.

Keywords: Government of Arms; Independence; Piauí.

\footnotetext{
${ }^{1} \mathrm{O}$ termo "dissidente" foi retirado do vocabulário das fontes utilizadas para se referir ao comportamento contrário ao governo português. Ao longo do texto, significará as tropas alinhadas à independência do Brasil.

* Mestrando do Programa de Pós-Graduação em Ciência Política (PPGCP) da Universidade Federal do Piauí (UFPI). Bolsista Capes. Membro do Núcleo de Estudo e Pesquisa em História do Piauí Oitocentista (CNPq). E-mail: luis-albano@ hotmail.com.

** Doutor em História (UFF). Professor da Universidade Federal do Piauí (UFPI) e líder do Núcleo de Estudo e Pesquisa em História do Piaú Oitocentista (CNPq). E-mail: johnysant@ gmail.com.
} 


\section{INTRODUCÃO}

O período de independência da província do Piauí encerra ampla rede de interesses públicos e privados, através da agência de sujeitos que protagonizaram os embates políticos, sociais e culturais em torno da separação entre Brasil e Portugal. A virada entre o ano de 1822, quando circularam com mais frequência as ideias que eram capazes de questionar o sistema colonial português, e o ano de 1823, quando se iniciou a série de mudanças governamentais em virtude do surgimento de governos sediciosos paralelos, faz-se verdadeira fronteira entre o governo português e o nascente Império do Brasil. Neste movimento de ações e reações entre sujeitos dissidentes e respostas da administração portuguesa concentraremos a nossa discussão.

Este trabalho visa apreender exatamente as contradições expostas no momento sensível da adesão do Piauí à independência, questionando aquilo que estava em curso no âmbito nacional, no plano da circulação de ideias, e suas possibilidades na realidade local, com suas adaptações. Através de sujeitos como João José da Cunha Fidié, Manuel de Sousa Martins, João Cândido de Deus e Silva, Simplício Dias da Silva, entre outros, buscamos apreender as relações forjadas neste momento de transição jurisdicional entre Lisboa e as juntas de governo já obedientes ao Rio de Janeiro. A partir desta condição particular, questionamos o grau de participação destes sujeitos no desenho do movimento de independência, em face das estruturas governativas ainda vigentes.

A escolha destes sujeitos se dá pelos cargos que ocuparam, a saber: governador das armas, presidente da Junta de Governo da Província, juiz-de-fora, entre outros. As fontes aqui trabalhadas são majoritariamente do Arquivo Histórico Ultramarino, através do Projeto Resgate, compondo um quadro de correspondências oficiais, além das fontes reunidas por Pereira da Costa em sua obra Cronologia histórica do Estado do Piauí. Mas também buscamos elencar algumas correspondências particulares, bem como relatos que nos ajudem a esquadrinhar o que acontecia na província do Piauí entre 1822 e 1823 . Com isso, pretendemos também demonstrar como as particularidades locais são importantes para melhor entender a composição do quadro geral da independência nacional. ${ }^{2}$

\footnotetext{
${ }^{2}$ Há uma importante historiografia referente ao processo de independência no Piauí, comumente os historiadores de vocação do século XX para além dos clássicos do século XIX, trabalhados no texto, e os historiadores profissionais. Do primeiro grupo de trabalhos clássicos inclui: BRANDÃO, Wilson de Andrade. História da independência no Piauí. Teresina: FUNDAPI, 2006; BRITO, Anísio. Independência do Piauí. Teresina, 1931; BRITO, Bugyja. O Piaui e a Unidade Nacional. Teresina: Cia. Editora do Piauí, 1973; CHAVES, Joaquim. O Piauí nas lutas
} 
Analisaremos o envio do major português João José da Cunha Fidié para ocupar o cargo de governador das armas da província do Piauí, como uma resposta de Lisboa à crescente difusão das ideias separatistas, dada a urgência de se manter o território que servia de ligação entre o Norte e o Sul do país; ${ }^{3}$ além disso, faz-se mister saber sua relação com a Junta de Governo em exercício na Província, na medida em que ocupou lugar de garantidor direto dos interesses de Portugal no Piauí. Em seguida, buscaremos demonstrar como os dissidentes reagiram a isto, criando estruturas governativas paralelas e arregimentando, a partir de seus interesses próprios, forças ainda que rudemente armadas para garantir a liberdade que procuravam. Desta forma, poder-se-á ter noção do movimento em suas duas faces e suas respectivas compreensões da realidade.

\section{O GOVERNADOR DAS ARMAS DA PROVÍNCIA DISSIDENTE}

Os primeiros indícios de adesão à independência no Piauí se deram no litoral, no termo da vila de São João da Parnaíba, que abrigava importante porto de escoação das produções dos sertões, especialmente relacionado ao gado e seus derivados. Muito embora a navegação no litoral piauiense não fosse propícia para além da cabotagem, o trânsito presente no porto da Parnaíba era considerável, ainda mais por representar, através do rio homônimo, uma importante veia aberta para o interior das províncias do Piauí e Maranhão. ${ }^{4}$ Os sujeitos dessa

da independência do Brasil. Teresina: Alínea Publicações Editora, 2005; NEVES, Abdias. A Guerra do Fidié. $4^{\mathrm{a}}$ Ed. Teresina: FUNDAPI, 2006; NUNES, Odilon. Pesquisa para a história do Piauí: a Independência do Brasil, especialmente no Piauí. Manifestações republicanas. A ordem. Teresina: FUNDAPI, 2007; SANTANA, R. N. Monteiro; SANTOS, Cineas. (Orgs.) O Piauí e a Unidade Nacional. Teresina: FUNDAPI, 2007. Dentro desse conjunto, há ainda as memórias do próprio Fidié: FIDIE, João José da Cunha. Varia Fortuna de um Soldado Português. Teresina: Fundapi, 2006. Dos trabalhos mais recentes, que compõem o segundo grupo (historiadores profissionais de formação), existem as pesquisas tratadas a partir de novas perspectivas, no campo da nova história social e política, aqui encontramos os estudos de: ARAÚJO, Johny Santana de. O Piauí no processo de independência: contribuição para construção do império em 1823. Clio: Revista de pesquisa histórica, Recife, v. 33, n. 2, pp. 29-48, jul./dez. 2015; DIAS, Claudete Maria Miranda. O outro lado da história: o processo de independência do Brasil visto pelas lutas no Piauí - 1789-1850. 1999. Tese de Doutorado em História, IFCS/UFRJ, 1999; MOURA, Iara Conceição Guerra de Miranda. A visão da história social sobre a "batalha do Jenipapo". Cadernos de Teresina, v. 39, 2008, pp. 77-83. E o estudo de pesquisadores diletantes como o trabalho de: CASTRO, Francisco. A guerra do Jenipapo: a independência do Piauí. São Paulo: FTD, 2002. NETO, Adrião. Epopeia do Jenipapo. Teresina: Rima, 2007; MARQUES, Renato Neves. 19 de outubro o dia do Piauí. Parnaíba: Ed. Sistema Fercomercio, 2000. Há ainda os importantes trabalhos no campo da arqueologia militar, que tratam transversalmente sobre a narrativa histórica da batalha do Jenipapo, as referências são os trabalhos de: CARVALHO, Maria do Amparo Alves de. Batalha do Jenipapo: Reminiscências da cultura material em uma abordagem arqueológica. Porto Alegre: PUC RS. Tese de Doutorado, Programa de Pós-Graduação em História da Faculdade de Filosofia e Ciências Humanas da Pontifícia Universidade Católica Rio Grande do Sul, 2014; CASTELO BRANCO, Anne Kareninne Souza. Arqueologia em Campos de Batalha: acampamento, caminhos antigos das tropas da Batalha do Jenipapo. Dissertação (Mestrado em Arqueologia), Universidade Federal do Piauí, 2018. Destacamos ainda um trabalho sobre a participação de indígenas da Província do Ceará nas lutas empreendidas no Piauí: COSTA, João Paulo Peixoto. Mata que é corcunda! Os índios do Ceará na guerra de independência do Piauí. Habitus, v. 14, n. 2, jul./dez. 2016, pp. 243-262.

${ }^{3}$ ARAÚJO, 2015

${ }^{4}$ CELESTINO DA SILVA, Mairton. Um caminho para o Estado do Brasil: colonos, missionários, escravos e índios no tempo das conquistas do Estado do Maranhão e Piaú, 1600-1800. Tese (Doutorado em História). Universidade Federal de Pernambuco, Recife, 2016 , p. 21. 
faixa litorânea conviviam com tensões políticas já em $1821 .^{5}$ Ainda assim, também os sertões do Piauí estavam conectados em trânsitos comerciais entre a Bahia, o Pernambuco, Ceará e Maranhão pelo fornecimento de carne seca, gado vacum e cavalar, couro entre outros produtos que abasteciam um mercado interno. ${ }^{6}$

Após a Revolução pernambucana de 1817, o controle censório sobre temas republicanos ou que fomentassem qualquer centelha de independência tornou-se ainda mais rígido, buscando acompanhar esse trânsito de sujeitos e mercadorias. De fato, desde as reformas pombalinas, as publicações clandestinas concorriam com a fiscalização que contrastava com as "luzes" do humanismo português. ${ }^{7}$ Em 1818, chegou ao Governo do Piauí uma provisão proibindo a entrada e publicação do periódico intitulado $O$ Português,${ }^{8}$ determinando também que nenhum vassalo do reino e seus domínios recebesse, vendesse ou espalhasse por qualquer meio o mesmo jornal, sob a pena das mesmas leis que retinham quaisquer livros ou papeis que circulassem sem licença. ${ }^{9} \mathrm{O}$ controle estabelecia-se através da instauração de devassas e o envio de tropas capazes de sufocar qualquer movimentação contrária à ordem do reino.

Era comum a movimentação de ofícios entre os governos das províncias e Lisboa, através do Rio de Janeiro, dando conta do estado em que se encontrava cada uma, variando entre "palco de agitações" e "a mais perfeita paz". ${ }^{10}$ Em parte, como resposta da coroa portuguesa, atenta aos rumos incontornáveis que os eventos políticos tomavam no Sul do país e precavendo-se quanto a manter ao menos o Norte sob seu controle, a posição estratégica da província do Piauí em relação ao Maranhão e as demais províncias ainda mais ao Norte levou D. João VI a enviar um experiente militar português para, em Oeiras, resguardar tal posição através do Governo das Armas do Piauí.

\footnotetext{
${ }^{5}$ Concordamos com a perspectiva metodológica de François Furet em sua análise sobre a Revolução Francesa, onde demonstra que as tensões existentes no ambiente pré-revolucionário não induzem necessariamente à revolução. No caso do Piauí, há que se considerar ainda a reverberação da Revolução Liberal de 1820. Cf. FURET, François. Pensando a Revolução Francesa. Rio de Janeiro: Paz e Terra, 1989.

${ }^{6}$ A autora Isnara Pereira Ivo analisa a formação de mercados internos ao redor de explorações destinadas à metrópole, no caso específico das minas de ouro da Bahia e de Minas Gerais. Sobre isso, cf. IVO, I. P. Homens de caminho: trânsitos culturais, comércio e cores nos sertões da América portuguesa. Século XVIII. Vitória da Conquista: Edições UESB, 2012, p. 229.

${ }^{7}$ GALVES, Marcelo Cheche. Ao público sincero e imparcial: imprensa e independência na província do Maranhão (1821-1826). São Luís: Café\&Lápis; Editora UEMA, 2015, p. 90.

${ }^{8}$ O periódico foi editado em Londres entre 1814 e 1826. Não conseguimos informações sobre sua circulação no Piauí, apenas sobre a ordem de proibição. Cf. FERNANDES, Mario Luiz. O discurso de O Portuguez e a Corte portuguesa no Brasil. 2015. 108 f. Pesquisa (Pósdoutorado) - Curso de Jornalismo, Departamento de Ciências Empresariais e da Comunicação, Universidade Fernando Pessoa, Porto, 2015. ${ }^{9}$ PEREIRA DA COSTA, F. A. Cronologia histórica do Estado do Piauí. Teresina: APL; FUNDAC; DETRAN, 2010, p. 51.

${ }^{10}$ Durante nossas pesquisas no acervo digital do Arquivo Histórico Ultramarino (AHU), encontramos diversos ofícios dos governadores dirigidos aos ministros do governo português, dando conta do estado em que se encontrava a província, seja de paz ou de agitação, informando as medidas a serem tomadas no estabelecimento da ordem. Utilizaremos, aqui, apenas os ofícios ligados ao Governo das Armas entre os anos $1822 / 1823$.
} 
Data de 9 de dezembro de 1821, no Palácio de Queluz, a nomeação de Fidié, encaminhada pelo próprio rei, que muito saudava o major do Exército Nacional e Real. Justificando sua escolha para o Governo das Armas do Piauí, o rei destacou a confiança e experiência de zelo e préstimo nos serviços do Exército, demonstrando certa proximidade. A esta, Fidié respondeu que estava pronto para partir ao seu destino, suplicando ao rei que lhe desse passagem ao Maranhão em qualquer embarcação, o que foi atendido pelo Ministro de Estado de Negócios da Marinha, disponibilizando a charrua Gentil Americana para sua viagem, acompanhado de um criado. ${ }^{11}$ Em janeiro de 1822, Fidié solicitou ainda ao rei as "comedorias do estilo" para que se prontificasse a sair em destino ao Piauí. ${ }^{12}$ Já em abril do mesmo ano, solicitou livre passagem pelas fortalezas e visitas de registro, na passagem pelo Maranhão. ${ }^{13}$

Em agosto de 1822, Fidié oficiou sua posse no Governo das Armas do Piauí ao secretário de estado dos Negócios Estrangeiros e de Guerra, Cândido José Xavier, lamentando a impossibilidade de enviar o mapa das forças da província, mas participando com "particular satisfação" a tranquilidade em que se achavam os "Corpos Militares e mais habitantes", em quem observou "firme aderência ao Sistema Constitucional e obediência a Sua Majestade e ao Soberano Congresso". ${ }^{14}$ Em outro ofício, de setembro do mesmo ano, Fidié reforçou aquilo que já havia dito sobre os "sentimentos" dos povos do Piauí, do que tinha concluído a partir de suas diligências, e acrescentou ainda a "perfeita inteligência com que marcham os negócios" de seu governo com os do Governo Provisório, presidido pelo padre Mathias Pereira da Costa, com o qual contava "sempre ir de comum acordo". 15

Mesmo com a presença de Fidié em Oeiras, junto de forças militares arregimentadas pelo governo português, os acontecimentos na província conduziam cada vez mais à instabilidade política. Antes de sua chegada, ainda em maio de 1821, o brigadeiro Manuel de Sousa Martins e o capitão Manuel de Sampaio, comandante da guarnição da cidade de Oeiras, denunciaram ao governador Elias José Ribeiro de Carvalho uma tentativa de revolução ${ }^{16}$ por

\footnotetext{
${ }^{11}$ Arquivo Histórico Ultramarino, Piauí, Caixa 31, Documento 1627.

12 Arquivo Histórico Ultramarino, Piauí, Caixa 31, Documento 1611.

${ }^{13}$ Arquivo Histórico Ultramarino, Piauí, Caixa 31, Documento 1636.

${ }^{14}$ Arquivo Histórico Ultramarino, Piauí, Caixa 31, Documento 1649.

${ }_{15}$ Arquivo Histórico Ultramarino, Piauí, Caixa 31, Documento 1659

${ }^{16}$ A documentação sobre o referido caso assim o trata ao reportá-lo ao Secretário de Estado dos Negócios Estrangeiros e de Guerra, no Rio de Janeiro, mas não se trata de qualquer germinação da Revolução que se inaugurou com a adesão à independência, e sim um fato isolado, muito embora o escrivão Antônio Maria Caú tenha continuado a incitar a desobediência em outras partes do Piauí, como na Parnaíba.
} 
parte de Antônio Maria Caú, escrivão da Junta da Fazenda, e demais cúmplices, que foram presos e remetidos à vila da Parnaíba, tendo ainda este fato reverberado em toda a província por muito tempo. ${ }^{17}$ Aconteceu que o escrivão deu início a um imbróglio quando acusou o Governador Elias José Ribeiro de Carvalho de ocultar ordens recebidas de Lisboa e atrasar o juramento à Constituição das Cortes Gerais portuguesas, motivo este que seria utilizado pelo mesmo para dar início a um golpe que mudaria o governo do Piauí.

O Governador, contudo, defendeu-se apresentando provas de que não havia ocultado informações e marcou o solene juramento à Constituição, ao qual não compareceu o escrivão Antônio Maria Caú, que continuou a dar "exercício ao seu rebelde gênio, vociferando contra as Autoridades, contra a Tropa e aqueles que não quiseram ter parte na sua horrorosa facção", além de desobedecer ordens das mais diversas autoridades, conforme oficiou. ${ }^{18} \mathrm{O}$ caso foi reportado ao Rio de Janeiro para esperar a deliberação do rei, e Caú permaneceu na Vila da Parnaíba recebendo seus vencimentos enquanto esperou uma resolução, dizendo em sua defesa que estava sendo castigado pelo exercício de sua função em "extirpar muitos abusos [...] lesivos à Fazenda", nos quais o Governador tinha parte "praticando" ou "consentindo", e ressaltou a sua inocência. ${ }^{19}$

Neste mesmo ano, Elias José Ribeiro de Carvalho oficiou ao ministro do Reino, Inácio da Costa Quintela, observando a urgente vontade de setores da população que pediam um governo provisório à semelhança do que existia na Bahia, solicitando que Sua Majestade demitisse, pois, o Governo, e o substituísse da forma de seu real agrado, temendo um motim, "para o que estes povos estão muito inclinados". ${ }^{20}$ Era uma forma de adesão ao Sistema Constitucional que derivou da Revolução do Porto, em 1820.

Outro ofício do mesmo ano, dirigido ao Ministro de Estado dos Negócios do Brasil, desembargador Pedro Álvares Dinis, informava sobre ameaças ao Governador e demais autoridades através de recorrentes pasquins para justificar a instalação do Governo Provisório, ato considerado indispensável diante da "opinião pública e vontade geral dos povos, que nesta parte manifesta cada vez maior adesão à [...] constituição, com a qual é mais conforme o

\footnotetext{
${ }^{17}$ PEREIRA DA COSTA, 2010, p. 63-4.

${ }^{18}$ Arquivo Histórico Ultramarino, Piauí, Caixa 31, Documento 1640.

${ }^{19}$ Arquivo Histórico Ultramarino, Piauí, Caixa 31, Documento 1640.

${ }^{20}$ PEREIRA DA COSTA, 2010, p. 65.
} 
governo provisório, que o passado, que era geralmente olhado com ódio e rancor [...]". ${ }^{21}$ A cada ato de agravo contra o governo português, que cada vez mais partia das próprias pessoas investidas em cargos estratégicos, as autoridades locais que permaneciam fiéis a Portugal logo cuidavam em reafirmar seus votos de obediência em vivas e aclamações, jurando solenemente observar a Constituição portuguesa em eventos públicos.

No caso da vila da Parnaíba, quando o trânsito de pessoas e mercadorias tomou uma dimensão significativa, sentiu-se a necessidade da criação, em 1811, do posto de Juiz de Fora, com jurisdição em um território superior ao da própria vila, descentralizando a jurisdição da capital. ${ }^{22}$ De fato, quando a tensão separatista se fez sentir em 1822, a Junta do Governo sediada em Oeiras recorreu ao juiz de fora da Parnaíba para que fizesse encaminhamentos, contudo, as autoridades locais da Parnaíba declararam apoio à independência. Chegou à capital, em setembro, notícias de que um popular chamado Lourenço de Araújo Barbosa estava alterando a "ordem pública", "atentando contra o sistema constitucional e união do reino". Imediatamente pediu-se que o juiz de fora João Cândido de Deus e Silva encaminhasse o dito suspeito e abrisse devassa para apurar se havia também produzido pólvora, que deveria ser apreendida. ${ }^{23}$

Enquanto a Junta do Governo cuidava desses assuntos na capital, de lá também partiu ordem do governador das armas para que se marchasse para Campo Maior, vila próxima da Parnaíba e de mesma jurisdição do juiz de fora, um destacamento estacionado na vila de Marvão. Lourenço Barbosa de fato havia iniciado a produção de pólvora, demonstrando já a proximidade de um motim com a possível separação entre Brasil e Portugal, que agora se plasmava diante da opinião pública através da produção e circulação de escritos. ${ }^{24}$ Mesmo sabendo que as autoridades locais eram coniventes com tudo que estava acontecendo, onze portugueses moradores da vila da Parnaíba compareceram à Câmara solicitando a remoção do comandante primeiro-tenente Joaquim Timóteo de Brito, brasileiro, por não lhe terem confiança nem garantia de postura séria frente aos pronunciamentos independentes. Não sendo atendidos, protestaram contra João Cândido de Deus e Silva, acusando-o de não punir os sediciosos e reiterando que não se sentiam seguros com autoridades brasileiras. ${ }^{25}$

\footnotetext{
${ }^{21}$ PEREIRA DA COSTA, 2010, p. 71

${ }^{22}$ PEREIRA DA COSTA, 2010, p. 28

${ }^{23}$ PEREIRA DA COSTA, 2010, p. 81.

${ }^{24}$ PEREIRA DA COSTA, 2010, p. 81.

${ }^{25}$ PEREIRA DA COSTA, 2010, p. 82
} 
De fato, João Cândido não abriu devassa, mas enviou ofício ainda em setembro de 1822, dirigido à Junta do Governo, argumentando que era natural a separação entre Brasil e Portugal, vez que a parte "maior, mais rica, mais populosa" do país já havia declarado apoio à causa da independência, não sendo favorável que se assista "de sangue frio o país dividido, seguindo o Sul um sistema e o Norte outro", fazendo referência à dinâmica iniciada no Rio de Janeiro. O mesmo João Cândido que havia discursado anos antes na Câmara da Vila da Parnaíba por ocasião do aniversário de D. João VI, e por diversas vezes discursado também nos atos de juramento à Constituição, apontou a circulação de "proclamações, manifestos e notícias públicas", com as quais os povos se agradavam e entusiasmavam, como elementos suficientes para que se respeitasse a opinião pública, já que para ele "ou os povos querem e ninguém lhes pode resistir sem risco, ou não querem e então assim o declaram". ${ }^{26}$

No mês seguinte a esses acontecimentos, em 19 de outubro de 1822, a vila da Parnaíba declarou oficialmente sua adesão à independência do Brasil, entre as "mais vivas e ruidosas manifestações populares". O movimento levado a cabo pelo próprio João Cândido, seu amigo coronel Simplício Dias da Silva, tenente Joaquim Timóteo de Brito, Leonardo de Carvalho Castello-Branco entre outros líderes e populares,${ }^{27}$ foi visto por Pereira da Costa como resposta direta à repressão causada pela presença do major Fidié. O sistema constitucional teria instaurado no Brasil uma nova ordem que fazia crescer, paradoxalmente, o desejo de liberdade, germinando a ideia de emancipação política. ${ }^{28}$ As notícias exatas e minuciosas da proclamação da independência em Parnaíba, ocorrida a 19 de outubro, chegaram a Oeiras em 5 de novembro, mas os boatos já circulavam nesta capital desde o mês anterior. ${ }^{29}$ As reações às notícias foram desde o apoio e adesão ao "partido" da independência, até o repúdio das câmaras das vilas, como a de Jerumenha, que ainda reafirmou seu juramento à Constituição portuguesa. ${ }^{30}$

Deliberou-se então pela imediata partida do governador das armas junto de uma expedição militar, composta de toda a tropa de guarnição da cidade, deixando no comando de

\footnotetext{
${ }^{26}$ PEREIRA DA COSTA, 2010, p. 82-3.

${ }^{27}$ Muito embora a participação de "populares", no sentido de oriundos das massas de povo, careça de maior aprofundamento, trabalhos já citados neste artigo dão conta da participação de índios e milícias cearenses nas batalhas do Piauí, além dos escravos e ajudantes de Simplício Dias e de Leonardo de Carvalho Castello-Branco, respectivamente. Notório é o interesse dos líderes piauienses em angariar o apoio das lideranças indígenas, especialmente do Ceará. Sobre isto, cf. COSTA, João Paulo Peixoto. Na lei e na guerra. Políticas indígenas e indigenistas no Ceará (1798-1845). Teresina: EDUFPI, 2018.

${ }^{28}$ PEREIRA DA COSTA, 2010, p. 83.

${ }^{29}$ PEREIRA DA COSTA, 2010, p. 85.

${ }^{30}$ PEREIRA DA COSTA, 2010, p. 91.
} 
Oeiras o capitão português Agostinho Pires, a quem o governo demonstrava confiança pela sua contrariedade às ideias de independência. Além disso, a Junta do Governo redigiu uma proclamação aos habitantes da vila da Parnaíba, observando a ingratidão que não merecia uma nação "respeitada pelos povos estrangeiros", pela qual se queria romper "sagrados e indissolúveis vínculos" com "nossos regeneradores, nossos generosos benfeitores" que acabavam de libertar-nos. Conclamava ainda a sustentar o primeiro juramento à Constituição portuguesa, vez que seriam reconhecidos como perjuros, entregues às paixões e ódios particulares, desejando a "glória" de ver a Parnaíba restituída à "antiga fidelidade". 31

Temendo, pois, a aproximação do exército comandado por Fidié, os dissidentes partiram para a vila de Granja, no Ceará, onde dispunham de amigos simpatizantes da causa da Independência, visando angariar apoio necessário para retornar ao Piauí. O governador das armas oficiou, em dezembro de 1822, ao secretário de estado de Negócios Estrangeiros e Guerra, sua chegada na vila da Parnaíba, tendo feito passar em linha a tropa, no largo da Matriz e da Casa da Câmara, ocasião em que "se remediaram os acontecimentos do dia 19 de outubro, restituindo [Parnaíba] ao sistema Constitucional". Fidié destacou que estes eventos públicos foram acompanhados por muitas pessoas, que "voluntariamente se ajuntou" na caminhada em sessão da Câmara até a igreja, onde se cantou Te Deum "assistido cheio de alegria e com profundo respeito" e se deu vivas ao rei, às Cortes de Lisboa, à Constituição e à santa religião. ${ }^{32}$

Segundo o relato desenhado neste mesmo ofício dirigido por Fidié a Cândido José Xavier, o ato de desagravo contou com toda a pompa digna da cerimônia, a saber: três cargas de "fogo de alegria", acompanhada, cada uma, por uma salva de sete tiros de canhão da embarcação Infante Dom Miguel, muitos repiques de sinos, foguetes e orquestra de música que tocava durante o "tempo das luminárias". Além disso, depois se acrescentou mais um viva, à união de Portugal e Brasil, "repetidos com louvável entusiasmo".

Apenas depois disto mencionou a fuga dos "principais mentores" da adesão à independência para o Ceará, onde estariam "diligenciando seduzir aqueles povos", e para onde muitos outros continuavam a ir em “comissões". Explicou que o brigue Infante Dom Miguel encontrava-se na vila a pedido da Câmara, diante das desagradáveis e aterradoras notícias que

\footnotetext{
${ }^{31}$ PEREIRA DA COSTA, 2010, p. 86-90.

${ }^{32}$ Arquivo Histórico Ultramarino, Piauí, Caixa 31, Documento 1667
} 
circulavam, préstimo pelo qual agradeceu ao comandante, pois já se achava a dita vila "segura e quieta, não obstante haverem os sediciosos pretendido perturbar os espíritos". No mais, indicou certa preocupação com a situação do Ceará e apenas solicitou "força auxiliadora" para conter qualquer ânimo. ${ }^{33}$

A Província do Maranhão muito comemorou, já que sua posição era sensível à fronteira com o Piauí, fazendo circular incansavelmente a notícia de que os independentes haviam evacuado a Vila da Parnaíba pela simples aproximação de Fidié, elogiando a estratégica providência do Governo em fazer visitar os pontos sem defesa. ${ }^{34}$ Antes mesmo de chegarem a Oeiras, as notícias sobre os acontecimentos da Parnaíba já circulavam em São Luís, através do periódico $O$ Conciliador, com as mais diversas ofensas contra João Cândido, Simplício Dias e os demais líderes independentes que haviam fugido para a Província do Ceará, onde mantinham contatos. A edição número 144 do periódico, de 27 de novembro de 1822, informava que "quase toda a Província do Piauí soube com indignação o procedimento dos habitantes da Parnaíba". ${ }^{35}$

Estas relações oficiais e a circulação de notícias indicam que os embates em torno da independência no Piauí foram mais profundos do que aparentam. Por trás de cada posicionamento, seja em favor da manutenção da ordem com a união do Brasil com Portugal ou através da separação e a formação de uma nação independente, havia interesses que motivavam os sujeitos a ocuparem espaços e defenderem suas intenções. Enquanto a administração local estava cada vez mais próxima dos intelectuais e comerciantes que defendiam a liberdade brasileira, o major Fidié achava-se dependente das ordens que chegavam da distante Lisboa ${ }^{36}$ e do apoio que permanecia apenas nas promessas do Maranhão. Quanto às elites locais que se mantinham fiéis ao governo português, casos que ainda merecem maior aprofundamento, a ajuda era incerta e flutuava entre ofícios das câmaras como a da supracitada vila de Jerumenha e os ataques dos dissidentes que as faziam sucumbir diante da falta de tropas portuguesas para cobrir todo o território, vez que o grosso acompanhava o major Fidié.

\footnotetext{
${ }^{33}$ Arquivo Histórico Ultramarino, Piauí, Caixa 31, Documento 1667.

${ }^{34}$ PEREIRA DA COSTA, 2010, p. 95.

35 O CONCILIADOR DO MARANHÃO, São Luís, 27 de nov. de 1822, No 144. Disponível em: < http://bndigital.bn.br/acervodigital/conciliador-maranhao/749524>. Acesso em 10 de mai. de 2021.

${ }^{36}$ Quando a Junta do Governo do Piauí recebeu a carta régia de nomeação de João José da Cunha Fidié para ocupar o governo das armas da mesma província, o major já se encontrava no exercício do cargo, segundo ofício enviado pela mesma Junta ao secretário de estado dos Negócios Estrangeiros e Guerra, Cândido José Xavier. Cf. Arquivo Histórico Ultramarino, Piauí, Caixa 31, Documento 1672.
} 


\section{DISSIDENTES NA PROVÍNCIA EM GUERRA}

Após a proclamação da independência na Vila da Parnaíba, a capital Oeiras tratava de resolver a configuração política interna da própria Província, convocando eleições para formação de nova Junta Provisória de Governo, por ordem do Ministro da Marinha e Ultramar. ${ }^{37}$ A esta eleição concorreu Manuel de Sousa Martins, futuro Visconde da Parnaíba, um dos homens mais influentes do Sul da Província do Piauí, que até então adotara uma postura de adesão à Portugal. Perdendo, porém, o pleito, o então brigadeiro aderiu ao movimento de independência, cedendo sua residência para reuniões que discutiram como se daria a proclamação de independência em Oeiras, com a máxima urgência. Na madrugada do dia 24 de janeiro de 1823, depois de tomada a Casa da Pólvora, cumpriu-se o plano e, pela manhã, Manuel de Sousa Martins tomou posse de uma nova Junta Provisória na posição de presidente. Estava criada uma estrutura administrativa paralela à administração portuguesa, também na capital.

Nesta altura, toda a província já convulsionava em suspeitas e inquirições contra sublevações que se espalhavam. Uma devassa realizada em Oeiras determinou a prisão de cinco pessoas, que deveriam ficar incomunicáveis sob o risco de resultar "perigosos acontecimentos", tendo por corpo de delito uma relação de quatro pasquins que haviam sido fixados em esquinas da cidade. ${ }^{38} \mathrm{~A}$ isto juntou-se a iminente ocupação da Província por tropas cearenses que vieram em socorro dos independentes, além de milícias mantidas pelos piauienses mais abastados. Não demorou para se iniciar um longo período de preocupação para o povo piauiense, que sentiu no cotidiano os dramas e a tensão da proximidade e realização de uma guerra.

Em ofício datado de 25 de janeiro de 1823, em Oeiras, o tenente-coronel Joaquim de Sousa Martins, irmão de Manuel de Sousa Martins, noticiou a aclamação de Dom Pedro como Imperador constitucional na capital do Piauí "pelos povos, Câmara, clero, tropa", unidos ao "sistema público de toda [a] Província, cujo sistema é o do Brasil inteiro", conforme "a vontade de nosso Augusto Imperador". A causa do Brasil deveria ser defendida pelos piauienses "com

\footnotetext{
${ }^{37}$ PEREIRA DA COSTA, 2010, p. 72.

${ }^{38}$ PEREIRA DA COSTA, 2010, p. 105
} 
a espada na mão". O ofício era dirigido também ao "ex-Governador das Armas, o Ilmo. Sr. João José da Cunha Fidié", a quem pediu que desfizesse as tropas que se achavam debaixo de sua ordem, por sua probidade, prudência e respeito à "opinião geral", que havia mudado de figura o Governo. Após solicitar tropas para guarnecer a capital, assinou como Governador das Armas. ${ }^{39}$

Ainda em Parnaíba, possivelmente sem notícia do que ocorrera em Oeiras, Fidié enviou ofício a Cândido José Xavier, datado de 27 de janeiro de 1823, informando que chegavam de diferentes partes notícias sobre investidas de tropas cearenses em direção à província do Piauí, colocando em risco também a província do Maranhão, o que exigia a presença de forças europeias, comandadas por um hábil oficial, segundo o pedido feito no ofício. As "fracas forças" da província não podiam socorrer ao mesmo tempo lugares tão distantes, além disso, a província do Ceará estava em "perfeita anarquia", situação na qual os constitucionais não podiam respirar sem a ajuda necessária, uma "força auxiliadora". Mesmo assim, Fidié prometeu sustentar suas forças contra "qualquer número de tropas e gentes que os sediciosos da Província do Ceará possam reunir".

Neste mesmo ofício estava anexo um documento do escrivão interino da Comarca da Parnaíba, informando que Fidié havia perguntado publicamente, no dia 18 de dezembro, se o povo preferia o juramento prestado às Cortes constituintes de Lisboa ou o voto de 19 de outubro, pela independência, ao que o presidente do senado da Parnaíba respondeu que unanimemente se estava pelo primeiro juramento. ${ }^{40}$ Um dia depois, Fidié solicitou ao rei promoção para José Gonçalves Coelho da Silva, alferes da primeira companhia do Regimento de Infantaria de Milícias, por seus merecimentos, préstimos e atividades, tendo se negado a jurar a independência no 19 de outubro, e ajudando o governo das armas com informações sobre os dissidentes. ${ }^{41}$ De fato, só em fevereiro Fidié escreveu um documento dando conta da adesão de Oeiras à independência e noticiando uma invasão à vila da Parnaíba, iniciando sua marcha de volta a Oeiras.

As elites intelectuais e políticas que haviam fugido para o Ceará com a marcha de Fidié em direção à Parnaíba, voltaram com tropas cearenses e encontraram a cidade desprotegida,

\footnotetext{
${ }^{39}$ Arquivo Histórico Ultramarino, Piauí, Caixa 31, Documento 1676.

${ }^{40}$ Arquivo Histórico Ultramarino, Piauí, Caixa 31, Documento 1679.

${ }^{41}$ Arquivo Histórico Ultramarino, Piauí, Caixa 31, Documento 1680
} 
vez que diversos outros pontos da província já precisavam das forças do governador das armas português. Enquanto a porção Sul da província contava com a atuação de Manuel de Sousa Martins na presidência da Junta Provisória do Governo independente, a faixa Norte era comandada pelos interesses de lideranças políticas e econômicas como o próprio João Cândido, que permaneceu em Granja, e o coronel Simplício Dias. Vindo da Província do Pará, onde nasceu em 1787, João Cândido de Deus e Silva seguiu notável carreira na magistratura, como apontou Sacramento Blake. Chegou a ser lente da Faculdade de Direito de São Paulo, mas pediu demissão um ano após sua nomeação e se aposentou como desembargador da Relação do Maranhão. Nobre dignitário da Ordem da Rosa e Cavaleiro da Ordem de Cristo, traduziu para o português e escreveu considerável número de obras. ${ }^{42}$

Mas aqui importa destacar sua participação intelectual na sedição da Vila da Parnaíba. João Cândido criou condições para que se declarasse a independência nas cidades sob sua jurisdição. Descrito como um homem ativo e de "sentimentos patrióticos", "pregou" ao povo e ensinou-lhe "o caminho da felicidade futura", preparando assim a Vila da Parnaíba, Piracuruca e, com a ajuda de amigos, também Campo Maior. ${ }^{43} \mathrm{O}$ coronel Simplício Dias, por sua vez, gozava de grande amizade com João Cândido, aderindo prontamente ao movimento separatista. Na verdade, seus motivos iam além do "patriotismo". Era um homem de grande influência na região e abastado proprietário. ${ }^{44}$ Seu pai, capitão Domingos Dias da Silva, era um dos maiores negociantes da região, contando com notável fortuna e uma próspera charqueada, contribuindo diretamente para a caracterização da Vila da Parnaíba como entreposto comercial de carne e couramas. Responsável por um trânsito constante com Lisboa e outras províncias, lutou pela construção de uma Alfândega no Porto da Parnaíba que tivesse trânsito livre, luta que foi continuada e alcançada por Simplício Dias, herdeiro de seus cabedais.

Domingos Dias da Silva, seu filho e demais negociantes foram responsáveis não apenas pela inserção da vila da Parnaíba em circuitos comerciais gerados pela criação de gado, mas também por uma efervescência cultural intrínseca à circulação de pessoas, mercadorias, técnicas e saberes nesta região, que era responsável por manter o diálogo entre os mares e os

\footnotetext{
${ }^{42}$ SACRAMENTO BLAKE, A. V. A. Diccionario bibliographico brazileiro. Volume 3. Rio de Janeiro: Imprensa Nacional, 1902 , p. 377.

${ }^{43}$ PEREIRA DA COSTA, 2010, p. 84

${ }^{44}$ PEREIRA DA COSTA, 2010, p. 93.
} 
sertões. ${ }^{45}$ Este diálogo estimulou sobremaneira a criação de vínculos comerciais e culturais que muitas vezes não passavam diretamente pelo centro regulamentador do Governo português, mas que eram alvo das políticas censórias destinadas às periferias, criando tensões que podem ser consideradas também como germinadoras da necessidade de independência. Prova disto, os recorrentes pedidos de criação de uma Alfândega no Porto da Parnaíba tinham como argumento principal, por parte de seus requerentes, o consequente aumento dos bens da Coroa, mas não deixavam de refletir o intenso fluxo comercial e o desejo dos negociantes de desfrutarem de trânsito direto e dos privilégios dos grandes centros comerciais, barrados pelo prejuízo da dependência burocrática. ${ }^{46}$

À época da adesão do Piauí à independência do Brasil, o coronel Simplício Dias gozava de posição social relevante ainda em consequência da indústria de charque iniciada por seu pai, além de grande prestígio por sua fausta fortuna, que lhe proporcionou a marca de posse de mais de 1.800 escravos, que inclusive foram armados e preparados para lutarem pela independência. Além de ocupar cargos da administração pública, solicitou por mérito de seus trabalhos o hábito da Ordem de Cristo e obteve carta de brasão de armas mesmo sendo filho legitimado, fato amplamente divulgado no periódico $O$ Conciliador, que o acusava de ser filho de uma mulata.

Sua fama incluía fatos como um cacho de banana de ouro com que presenteou o imperador D. Pedro I, a banda de música que mantinha em casa através de seus escravos, dentre outras façanhas. Na opinião de alguns viajantes que passaram pela Vila da Parnaíba e conheceram o coronel Simplício Dias, destacava-se sua opulência e apreço às belas-artes, para além das suas excentricidades. O inglês Henry Koster fez referência à sua admirável honra, e Tollenare escreveu em suas Notas Dominicais que o coronel vivia com um "luxo asiático", acolhendo bem os estrangeiros como um homem poderosamente rico. ${ }^{47}$

De fato, sua amizade com João Cândido de Deus e Silva proporcionou ao movimento de independência no Piauí a muito útil fusão de capital financeiro e cultural suficientes para sustentar com forças, dinheiro e intelectualidade as batalhas contra os portugueses. Foi preciso

\footnotetext{
${ }^{45}$ REGO, Junia Motta Antonaccio Napoleão do. Dos sertões aos mares: história do comércio e dos comerciantes de Parnaíba (1700-1950). Tese (Doutorado em História), Universidade Federal Fluminense, Niterói, 2010.

${ }^{46}$ REQUERIMENTO de Simplício Dias da Silva e Manuel Antônio da Silva Henriques ao príncipe regente D. João, solicitando que no caso de seu requerimento em que pedem a criação de uma alfândega na vila de São João da Parnaíba seja escusado, eles possam expedir seus navios sem escala em portos intermediários. [Manuscrito] Arquivo Histórico Ultramarino, Piauí, Caixa 28, Documento 1439.

${ }^{47}$ PEREIRA DA COSTA, 2010, p. 239.
} 
unir os abstratos motivos de uma independência que chegavam do Sul do país, aos interesses mais concretos que poderiam justificar estas batalhas, pondo fim ao tempo de paz. Ao darem voz à independência, estes dois líderes, juntos dos demais, souberam amalgamar todos os elementos necessários para impulsionarem os piauienses em direção a decisões que passavam necessariamente pela própria configuração política da Província do Piauí em relação às demais províncias e, quiçá, às demais nações, através do comércio.

João Cândido permaneceu no Ceará durante todo o embate da independência no Piauí, enquanto outros líderes intelectuais enfrentaram o campo de batalha, como foi o caso de Leonardo Castello-Branco, que chegou a prender um destacamento deixado por Fidié em Campo Maior, antes de ser preso no Maranhão e enviado a Lisboa. Entrementes, Manuel de Sousa Martins foi responsável por garantir o sucesso da independência a partir da capital Oeiras. A Junta do Governo do Piauí independente, enquanto tratava da proteção de portos próximos à Província do Maranhão, autorizou comandantes a exigirem dos donos de fazendas "todo o suprimento necessário, tanto de gado, como de mantimentos", que seriam "prontamente" pagos pelo Cofre da Tesouraria Geral da Junta da Fazenda. A exigência justificou-se com o pedido de "religiosa observância" à "salvação da Pátria", assim sendo, nenhum popular poderia escusarse ou valer-se de qualquer pretexto, já que o único objetivo dos verdadeiros "amantes da Pátria" era apenas a sua segurança. ${ }^{48}$

Esta "religiosa observação" foi seguida por muitos que se colocaram à disposição da causa da independência. Em carta de Julho de 1823, Francisco Germano informou ao CapitãoMor João Gomes Caminha a presença de um Sargento do Pará e um caboclo, que sondavam o rio para a saída do Major Fidié, e noticiou também que sua Guerrilha mantida no lugar Tresedella solicitava socorro, ao qual acudiria com a gente que mantinha em armas. ${ }^{49}$ Além disso, diversas foram as listas subscritas com doações de mantimentos para as tropas, dentre os quais: aguardente, milho, arroz pilado, farinha e outros produtos distribuídos em uma relação que apontava os nomes dos doadores e respectivas quantidades. ${ }^{50}$

\footnotetext{
${ }^{48}$ ACERVO MUSEU OZILDO ALBANO. Piauí, Junta do Governo. Encarrega Mathias de Souza Rabelo para a defesa de alguns portos e pede o apoio de todos os habitantes na independência. [Manuscrito]. Palácio do Governo de Oeiras, Fevereiro de 1823.

49 ACERVO MUSEU OZILDO ALBANO. Germano, Francisco. [Carta] 20 Julho 1823. Não consta [para] Capitão-Mor João Gomes Caminha, 1p. Carta ao Capitão-Mor.

${ }^{50}$ ACERVO MUSEU OZILDO ALBANO. Ferreira, Jozé Nunes. [Carta] 03 Agosto 1823, Barriguda [para] não consta, 1p. Relação de nomes com doações de mantimentos.
} 
Por outro lado, Francisco Queiroz registrou sua preocupação em relação a seu filho Luiz Plácido de Queiroz e dois negros seus, Manoel e Domingos, pedindo ao capitão Raimundo de Oliveira Falcão que os recomendassem aos seus amigos para que os tivessem vivos, assim podendo ter alívio. Pediu ainda novidades, pois havia ouvido "muitos tiros" e não sabia o que havia se passado por estar "com grandes cuidados". 51 Manuel Clementino de Sousa Martins reclamou, por sua vez, ao Capitão-Mor João Gomes Caminha, o sumiço de animais ferrados com a marca de seu tio, o próprio brigadeiro Manuel de Sousa Martins, que teriam sido levados por pessoas da tropa comandada pelo dito Capitão-Mor. ${ }^{52}$ José Thomaz denunciou ao mesmo Gomes Caminha a ação de quadrilhas que se aproveitaram da situação de guerra para saquearem todos que julgassem "mouros", dificultando o reconhecimento dos "verdadeiros independentes", levando-o a resolver por entregar mantimentos apenas com ordens escritas. ${ }^{53}$

Fidié lastimou a "inconstância e falta de caráter de alguns habitantes desta Província, que a tem reduzido ao mísero estado em que se acha", através de ofício dirigido a Cândido José Xavier em 16 de fevereiro. Foi a primeira comunicação em que não minimizou o movimento dos independentes, o que fez "com grande sentimento". Após tomarem a povoação de Piracuruca, "sem nenhuma resistência", os sediciosos fizeram as tropas do governador das armas recuarem em direção à Barra do Poti, o que se fez à custa de muitas deserções. Duas companhias inteiras, um comandante, um alferes com sua companhia e dez soldados de linha abandonaram as tropas e obrigaram Fidié a reconhecer que não restaria a terça parte da força que comandava. Além disso, chegava ao seu conhecimento os fatos das prisões dos membros do "antigo governo" e do Destacamento de Linha, além do vigário, por ocasião do "novo Governo civil e militar". 54

O mesmo ofício reconhecia ainda a falta de forças com que se encontrava Oeiras, havendo apenas a necessária para resguardar os "cofres nacionais", mas que "os influentes que moveram os acontecimentos do dia 24" haviam atinado para esta preocupação e solicitaram tropas do Ceará para guarnecer a capital. Apesar de reconhecer por suposição que "o resto da

\footnotetext{
${ }^{51}$ ACERVO MUSEU OZILDO ALBANO. Queiroz, Francisco. [Carta] 03 Julho 1823, Alegre [para] Capitão Raimundo de Oliveira Falcão, 1p. Recomendação de Luiz Plácido Queiroz e dois escravos para o serviço militar.

${ }^{52}$ ACERVO MUSEU OZILDO ALBANO. Sousa Martins, Manuel Clementino de. [Carta] 14 Junho 1823, Pindoba [para] Capitão-Mor João Gomes Caminha, 1p. Solicitação de informações sobre animais sumidos.

53 ACERVO MUSEU OZILDO ALBANO. Thomaz, José. [Carta] 26 Junho 1823, São José [para] Capitão-Mor João Gomes Caminha, 1p. Informações sobre o comportamento de quadrilhas que se passavam por independentes.

${ }_{54}$ Arquivo Histórico Ultramarino, Piauí, Caixa 31, Documento 1682.
} 
Província [estava] independente", Fidié deixou registrada sua posição de marchar para "restituir o Antigo Governo", contando com as mesmas promessas de apoio do Maranhão. ${ }^{55}$

Em decisão de marchar para Oeiras, Fidié acabou encontrando obstáculos maiores que os esperados, que o obrigaram a mudar de rota e buscar refúgio no Maranhão, ainda obediente a Portugal. A trajetória do Governador das Armas português desviou-se, a partir da Batalha do Jenipapo, em direção à Vila de Caxias, permanecendo aí até a sua capitulação. A historiografia clássica piauiense destina a estes acontecimentos do Jenipapo, e suas consequências, extensas páginas descritivas. ${ }^{56} \mathrm{O}$ que se percebe, contudo, diante desses acontecimentos, é um crescente enfraquecimento das forças portuguesas chefiadas por Fidié, mesmo em território maranhense, em detrimento de um protagonismo de forças independentes cearenses no território do Piauí, avançando em direção a um dos últimos redutos portugueses a esta altura da luta pela independência.

\section{ALGUMAS CONSIDERACÕES}

Findas as batalhas que completaram a adesão do Maranhão à independência do Brasil, o major português João José da Cunha Fidié comunicou a Manuel Gonçalves de Miranda, então ministro dos Negócios de Guerra de Portugal, sua prisão pelas tropas independentes em Caxias. No ofício, afirmou que acreditava fosse transferido para o Rio de Janeiro, junto com outros oficiais presos na mesma ocasião. ${ }^{57}$ De fato, o ofício dirigido ao ministro do Império João Severiano Maciel da Costa pela Junta do Governo da Província do Piauí em fevereiro de 1824 indicava sua viagem, atrasada pela "esterilidade da estrada da Bahia", ainda mais dificultosa por conta da "cruel seca que tem grassado nestes sertões". ${ }^{58}$ A viagem durou mais de um mês e, depois do Rio de Janeiro, retornou Fidié à Portugal, onde solicitou ao rei, em novembro de 1824, a ajuda de custo que lhe era devida e que não havia recebido ao assumir o Governo das Armas. Em março de 1827, seu pedido ainda tramitava na administração real portuguesa.

\footnotetext{
${ }^{55}$ Arquivo Histórico Ultramarino, Piauí, Caixa 31, Documento 1682.

${ }^{56}$ Cf. NEVES, 2006.

${ }^{57}$ Arquivo Histórico Ultramarino, Piauí, Caixa 31, Documento 1691.

${ }^{58}$ PEREIRA DA COSTA, 2010, pp. 199-202.
} 
A trajetória de Fidié no Piaú, e sua relação com outros sujeitos, nos ajuda a pensar as relações entre a metrópole e as autoridades locais no auge da tensão separatista, ou nos limites da fronteira de qualquer exercício de controle. Ao projetar o desejo de unir as províncias do Norte do país para manter o controle de parte do território brasileiro, a Coroa portuguesa esbarrou nas demandas locais ${ }^{59}$ que, por questões que transcendem este artigo, acabaram por assumir a postura separatista. Entrementes, vale ressaltar que aqui se buscou revelar as contradições inerentes a este momento político. A Junta do Governo chegou a oficiar afirmando que era mais útil ao comércio piauiense permanecer ligado a Portugal que ao Rio de Janeiro, além de conseguir manter melhor comunicação com aquele através do Maranhão que com este pela Bahia. ${ }^{60}$ Além disso, foram as tropas cearenses que tomaram lugar relevante nas lutas que se deram no Piauí, como demonstram os ofícios que relatam as preocupações da Junta do Governo com os abusos cometidos pelas tropas que voltavam para o Ceará após a consolidação da independência, e as dívidas assumidas.

De todo modo, essas contradições refletem a importância de considerar a profunda influência das instâncias locais no conjunto do Império português, reafirmando a metáfora do padre Antônio Vieira sobre o sol e a sombra, em analogia à posição dos funcionários em relação ao rei. ${ }^{61}$ A figura de Fidié representou, até as últimas consequências, a garantia dos interesses reais portugueses em terras piauienses, mas ao longo de sua trajetória, ele mesmo notou a instabilidade política que fez pendular não só as autoridades constituídas em poder, como também a opinião pública.

É mister perceber que a independência, no Piauí, não foi simplesmente aderida, mas também construída, como afirma Pereira da Costa, ${ }^{62}$ à sombra de muitos interesses e às custas de batalhas onerosas à Província e seus habitantes. Mesmo sendo este um constructo comum às demais lutas pela independência, já que adesão era um termo utilizado pelas próprias juntas, não custa lembrar que, em perspectiva mais ampla, cada construção leva a um caminho próprio de consequências sensíveis. Merecem essa observação não apenas pelo que têm a oferecer ao

\footnotetext{
${ }^{59}$ A saber, a instabilidade política, a busca das elites piauienses por cargos na administração e por maior autonomia em seus negócios, os interesses particulares das autoridades constituídas.

${ }^{60}$ PEREIRA DA COSTA, 2010, pp. 107-110

${ }^{61}$ Esta metáfora foi trabalhada por Mello e Souza (2006) em sua obra. Sobre os exercícios de interesses de natureza privada em relação às determinações reais, cf. IVO, 2012, p. 150

${ }^{62}$ PEREIRA DA COSTA, 2010, p. 218
} 
quadro geral da dinâmica inaugurada em setembro de $1822,{ }^{63}$ mas também para que as histórias não caiam no ufanismo. Lembrar que uma independência foi construída é também um convite à reflexão sobre como esta construção se deu, em toda a sua realidade e proficuidade.

\section{REFERÊNCIAS}

\section{Fontes}

ACERVO MUSEU OZILDO ALBANO. Ferreira, Jozé Nunes. [Carta] 03 Agosto 1823, Barriguda [para] não consta, 1p. Relação de nomes com doações de mantimentos.

Germano, Francisco. [Carta] 20 Julho 1823. Não consta [para] Capitão-Mor João Gomes Caminha, 1p. Carta ao Capitão-Mor.

Piauí, Junta do Governo. Encarrega Mathias de Souza Rabelo para a defesa de alguns portos e pede o apoio de todos os habitantes na independência. [Manuscrito]. Palácio do Governo de Oeiras, Fevereiro de 1823.

Queiroz, Francisco. [Carta] 03 Julho 1823, Alegre [para] Capitão Raimundo de Oliveira Falcão, 1p. Recomendação de Luiz Plácido Queiroz e dois escravos para o serviço militar.

Sousa Martins, Manuel Clementino de. [Carta] 14 Junho 1823, Pindoba [para] CapitãoMor João Gomes Caminha, 1p. Solicitação de informações sobre animais sumidos.

. Thomaz, José. [Carta] 26 Junho 1823, São José [para] Capitão-Mor João Gomes Caminha, 1p. Informações sobre o comportamento de quadrilhas que se passavam por independentes.

ARQUIVO HISTÓRICO ULTRAMARINO, Projeto Resgate - Piauí (1684 - 1828), ACL_CU_016, Cxs. 31 e 32. Disponível em: < http://resgate.bn.br/docreader/docmulti.aspx?bib=resgate>. Acesso em: jul. 2021.

HEMEROTECA DIGITAL DA BIBLIOTECA NACIONAL. O Conciliador do Maranhão, 1822, n. 144.

PEREIRA DA COSTA, F. A. Cronologia histórica do Estado do Piauí. Teresina: APL; FUNDAC; DETRAN, 2010.

\footnotetext{
${ }^{63} \mathrm{E}$ toda as consequências dos atos políticos que se deram no Rio de Janeiro a partir do 7 de setembro, os quais não adentramos aqui por considerarmos um campo suficientemente atendido pela historiografia. Preferimos, metodologicamente, acrescentar aquilo que as especificidades têm a oferecer, respeitando o espaço de um artigo.
} 
SACRAMENTO BLAKE, A. V. A. Diccionario bibliographico brazileiro. Volume 3. Rio de Janeiro: Imprensa Nacional, 1902.

\section{Obras Gerais}

ARAÚJO, Johny Santana de. O Piauí no processo de independência: contribuição para construção do império em 1823. Clio: Revista de pesquisa histórica, Recife, v. 33, n. 2, p. 2948, jul./dez. 2015.

BRANDÃO, Wilson de Andrade. História da independência no Piauí. Teresina: FUNDAPI, 2006.

BRITO, Anísio. Independência do Piauí. Teresina, 1931.

BRITO, Bugyja. O Piauí e a Unidade Nacional. Teresina: Cia. Editora do Piauí, 1973.

CARVALHO, Maria do Amparo Alves de. Batalha do Jenipapo: Reminiscências da cultura material em uma abordagem arqueológica. Porto Alegre: PUC RS. Tese (Doutorado em História), Pontifícia Universidade Católica Rio Grande do Sul, 2014.

CASTELO BRANCO, Anne Karenina Souza. Arqueologia em Campos de Batalha: acampamento, caminhos antigos das tropas da Batalha do Jenipapo. 2018. Dissertação (Mestrado em Arqueologia), Universidade Federal do Piauí.

CASTRO, Francisco. A guerra do Jenipapo: a independência do Piauí. São Paulo: FTD, 2002.

CELESTINO DA SILVA, Mairton. Um caminho para o Estado do Brasil: colonos, missionários, escravos e índios no tempo das conquistas do Estado do Maranhão e Piauí, 16001800. Tese (Doutorado em História), Universidade Federal de Pernambuco, Recife, 2016.

CHAVES, Joaquim. O Piauí nas lutas da independência do Brasil. Teresina: Alínea Publicações Editora, 2005.

COSTA, João Paulo Peixoto. Mata que é corcunda! Os índios do Ceará na guerra de independência do Piauí. Habitus, v. 14, n. 2, jul./dez. 2016, pp. 243-262.

COSTA, João Paulo Peixoto. Na lei e na guerra: políticas indígenas e indigenistas no Ceará (1798-1845). Teresina: EDUFPI, 2018.

DIAS, Claudete Maria Miranda. O outro lado da história: o processo de independência do Brasil visto pelas lutas no Piauí - 1789-1850. 1999. Tese (Doutorado em História), Universidade Federal do Rio de Janeiro, 1999.

FERNANDES, Mario Luiz. O discurso de O Portuguez e a Corte portuguesa no Brasil. 2015. Pesquisa (Pós-doutorado) - Curso de Jornalismo, Departamento de Ciências Empresariais e da Comunicação, Universidade Fernando Pessoa, Porto, 2015. 
FIDIE, João José da Cunha. Varia Fortuna de um Soldado Português. Teresina: Fundapi, 2006. FURET, François. Pensando a Revolução Francesa. Rio de Janeiro: Paz e Terra, 1989.

GALVES, Marcelo Cheche. Ao público sincero e imparcial: imprensa e independência na província do Maranhão (1821-1826). São Luís: Café\&Lápis; Editora UEMA, 2015.

IVO, I. P. Homens de caminho: trânsitos culturais, comércio e cores nos sertões da América portuguesa. Século XVIII. Vitória da Conquista: Edições UESB, 2012.

MARQUES, Renato Neves. 19 de outubro o dia do Piauí, Parnaíba: Ed. Sistema Fercomercio, 2000 .

MOURA, Iara Conceição Guerra de Miranda. A visão da história social sobre a "batalha do Jenipapo". Cadernos de Teresina, v. 39, 2008, p. 77-83.

NETO, Adrião. Epopeia do Jenipapo, Teresina: Rima, 2007.

NEVES, Abdias. A Guerra do Fidié. 4ª Ed. Teresina: FUNDAPI, 2006.

NUNES, Odilon. Pesquisa para a história do Piauí: a Independência do Brasil, especialmente no Piauí. Manifestações republicanas. A ordem. Teresina: FUNDAPI, 2007

RAMINELLI, Ronald J. Nobrezas do Novo Mundo: Brasil e ultramar hispânico, séculos XVII e XVIII. Rio de Janeiro: Editora FGV, 2015.

REGO, Junia Motta Antonaccio Napoleão do. Dos sertões aos mares: história do comércio e dos comerciantes de Parnaíba (1700-1950). Tese (Doutorado em História), Universidade Federal Fluminense, Niterói, 2010.

SANTANA, R. N. Monteiro. SANTOS, Cineas. O Piauí e a Unidade Nacional. Teresina: FUNDAPI, 2007. 